\title{
PENERAPAN OPEN SHORTEST PATH FIRST (OSPF) UNTUK MENENTUKAN JALUR TERBAIK DALAM JARINGAN
}

\section{THE IMPLEMENTATION OF OPEN SHORTEST PATH FIRST (OSPF) TO DETERMINE THE BEST PATH IN THE NETWORK}

\author{
Hari Antoni Musril, S.Kom., M.Kom \\ Jurusan Pendidikan Teknik Informatika dan Komputer (PTIK) \\ Institut Agama Islam Negeri (IAIN) Bukittinggi \\ kum ayik@yahoo.co.id
}

\begin{abstract}
Abstrak
Jaringan komputer skala besar sering kali menghadapi masalah dalam komunikasi data. Transmisi datanya membutuhkan waktu yang lama karena pemilihan protokol routing yang tidak tepat. Protokol routing yang dipilih tidak dapat memberikan alternatif jalur terbaik untuk melewatkan paket data. Penelitian ini menguji kemampuan protokol routing Open Shortest Path First (OSPF) dalam pemilihan jalur terbaik. Sebagai protokol routing pembanding dipilihlah Routing Information Protocol version 2 (RIPv2). Penelitian ini membandingkan jalur terbaik yang dihasilkan oleh OSPF dan RIPv2. OSPF merupakan protokol routing yang sering digunakan dalam jaringan skala menengah dan besar. OSPF mendistribusikan informasi routing antara router-router autonomous system (AS). OSPF merupakan protokol routing yang menggunakan algoritma linkstate untuk membangun dan mengitung jalur terbaik ke semua tujuan yang diketahui. Algoritma link-state juga dikenal dengan algoritma dijkstra atau algoritma shortest path first (SPF). Algoritma dijkstra diterapkan dalam protokol OSPF untuk memilih rute terbaik yang harus ditempuh oleh suatu paket data dari suatu alamat asal agar sampai di alamat tujuan dengan nilai satuan beban (cost metric) terkecil. Dalam teori graf, algoritma dijkstra dimanfaatkan untuk memilih lintasan terpendek antara dua simpul dari suatu graf yang merupakan representasi topologi jaringan. Sedangkan RIPv2 merupakan protokol distance vector yang menggunakan hitungan lompatan dalam pengukurannya. Jalur yang memiliki hop count yang lebih rendah akan dipilih untuk melewatkan paket data. Berdasarkan pada percobaan yang telah dilakukan, protokol routing OSPF dapat memberikan pilihan jalur terbaik (best path) dalam mengantarkan paket data. Sementara RIPv2 secara spesifik tidak dapat menghasilkan jalur terbaik.
\end{abstract}

Kata Kunci : open shortest path first (OSPF), algoritma djikstra, routing protocol, link-state, router, jalur terbaik

\begin{abstract}
Large-scale computer networks often face problems in data communications. Data transmission takes a long time due to the inappropriate selection of routing protocols. The selected routing protocol can not provide the best alternative path for get through the data packets. This research tested the ability of Open Shortest Path First (OSPF) routing protocol in the selection of the best path. As a comparison the chosen routing protocol is Routing Information Protocol version 2 (RIPv2). This research compares the best path generated by OSPF and RIPv2. OSPF is a routing protocol that often used in medium and large scale networks. OSPF distributes routing information between system autonomous routers (AS). OSPF is routing protocol that use link-state algorithm to
\end{abstract}


build and calculate the shortest path to all known destination. Link-state algorithms are also known as dijkstra algorithm or shortest path first (SPF) algorithms. Dijkstra's algorithm is applied in the OSPF protocol to choose the best route to be taken by a data packet from a source address in order to arrive at the destination address with the value of the unit load (cost metric) the smallest. In graph theory, Dijkstra's algorithm is used to choose the shortest path between two vertices of a graph that is a representation of the network topology. Whereas RIPv2 is a distanve vector protocol that uses a hop count in it's measurement. Path that have a lower hop count will be selected for get through the data packets. Based on experiments that have been carried out, the OSPF routing protocol can provide a selection of the best route (best path) to deliver data packets. While RIPv2 can not specifically generate the best path.

Keywords : open shortest path first (OSPF), dijkstra algorithm, routing protocol, link-state, router, best path

\section{PENDAHULUAN}

Jaringan komputer saat ini merupakan hal yang sangat dibutuhkan dalam sebuah organisasi. Aktivitas organisasi dapat berjalan lancar dengan adanya kemajuan teknologi untuk dapat mengirimkan data-data penting secara elektronik dan real time. Perkembangan sebuah organisasi juga akan berdampak pada semakin berkembangnya jaringan komputer yang dimiliki oleh organisasi tersebut. Perkembangan tersebut terjadi karena semakin banyaknya perangkat (hardware) yang terhubung pada jaringan komputer organisasi tersebut. Sehingga transmisi data yang diperlukan oleh organisasi menjadi sangat mudah dilakukan.

Transmisi data dalam jaringan komputer dapat berlangsung ketika semua syarat yang dibutuhkan untuk terjadinya interkoneksi jaringan komputer telah terpenuhi, baik dari sisi hardware maupun software. Salah satu syarat tersebut adalah setiap device berada dalam network yang sama. Pada jaringan yang besar akan terdapat lebih dari satu network, supaya transmisi data antar network dapat berlangsung dibutuhkan tambahan router. Router adalah piranti elektronik yang fungsinya mem-forward data antara jaringan komputer, dimana software dan hardware diseting untuk melakukan routing dan mem-forward informasi [1].

Routing adalah proses memilih lintasan yang akan ditempuh oleh sebuah paket pada suatu jaringan komputer untuk mengirim lalu lintas jaringan. Dalam proses routing ini, sebuah jaringan digambarkan sebagai sebuah graf berbobot dimana setiap interkoneksi antar titik dalam jaringan memiliki bobot atau nilai tertentu. Nilai ini dapat berupa bandwith, network delay, hopcount, path cost, load, reliability, dan biaya komunikasi. Setiap router harus mencari rute dengan biaya paling rendah [2].

Salah satu protokol routing yang dapat digunakan untuk menentukan jalur terbaik dalam pengiriman paket data di dalam jaringan skala besar adalah open shortest path first (OSPF). Dalam penelitian yang berjudul Perancangan dan Analisis Perbandingan Implementasi OSPF pada Jaringan IPv4 dan IPv6 [3], dijelaskan bahwa OSPF adalah suatu routing protokol Link State (LS) yang bersifat terbuka atau didukung berbagai perangkat jaringan. OSPF pada penelitian ini [3] dapat melakukan konvergensi secara cepat dan dapat menentukan jalur terbaik berdasarkan nilai cost yang diberikan. Penelitian [3] mengungkapkan bahwa OSPF melakukan update routing secara berkala sehingga ketika ada kesalahan atau kerusakan pada jaringan, OSPF akan menentukan jalur lain sebagai jalur cadangan. 


\section{DASAR TEORI}

\subsection{Routing}

Routing adalah proses menentukan rute dari host asal ke host tujuan [4]. Routing menentukan kemana datagram akan dikirim agar mencapai tujuan yang diinginkan [5]. Penelitian yang berjudul Implementasi Routing Protocol Open Shortest Path First (OSPF) pada Model Topology Ring [6], menjelaskan bahwa untuk mendapatkan hasil rute atau jalur yang bagus dibutuhkan desain arsitektur jaringan dalam pembangunan local area network multi area, terutama menentukan pemakaian routing protocol dalam topologi jaringan.

Penelitian [6] sebelumnya menjelaskan, routing protocol adalah algoritma yang digunakan dalam mengatur proses routing. Pengalamatan jalur/rute paket data yang akan dikirim akan diatur oleh routing protocol ini dengan membentuk tabel routing. Setiap routing protocol memiliki cara dan metode yang berbeda dalam melaksanakan tugasnya. Penelitian ini [6], juga menjelaskan bahwa informasi yang dibutuhkan router dalam melakukan routing yaitu : alamat tujuan/destination address, mengenal sumber informasi, menemukan rute, pemilihan rute, dan menjaga informasi routing.

Protokol routing menggunakan istilah yang disebut metric dalam menentukan jalur yang terbaik yang akan dipakai. Metric adalah suatu nilai hasil dari perhitungan algoritma yang dipakai oleh protokol routing yang dapat berupa jarak ke tujuan atau ongkos ke tujuan. Jenis metric yang dipakai bergantung pada jenis prototkol routing yang digunakan, dimana setiap jenis protokol routing menggunakan metric yang berbeda satu dengan lain [7].

\subsection{Open Shortest Path First (OSPF)}

Penelitian yang berjudul Implementasi Simple Port Knocking pada Dynamic Routing (OSPF) Menggunakan Simulasi GNS3 [8], menjelaskan bahwa Open Shortest Path First (OSPF) merupakan protocol routing link state dan digunakan untuk menghubungkan router-router yang berada dalam satu Autonomus System (AS), sehingga protocol routing ini termasuk juga dalam kategori Interior Gateway Protocol (IGP). Sehingga OSPF hanya dapat bekerja dalam jaringan internal suatu organisasi atau perusahaan. Pada jaringan internal, administrator jaringan memiliki hak penuh untuk mengatur dan memodifikasinya. Penelitian lainnya [9], mengungkapkan tahun 1989, versi pertama OSPF yang dikenal dengan OSPFv1 telah dipublikasikan di RFC (Request For Comments) 1131. Versi kedua yang disebut dengan OSPFv2 dikenalkan tahun 1998 yang didefinisikan di dalam RFC 2328. Tahun 1999 versi ketiga yaitu OSPFv3 yang dikhusukan untuk IPv6 telah dirilis di dalam RFC 2740.

OSPF menurut penelitian berikutnya [10], merupakan protokol perutean yang menggunakan konsep perutean hierarkis, artinya OSPF membagi-bagi jaringan menjadi beberapa tingkatan. Tingkatan-tingkatan ini diwujudkan dengan menggunakan sistem pengelompokan area. Dengan menggunakan konsep perutean hierarki ini sistem penyebaran informasi dalam protokol OSPF menjadi lebih teratur dan tersegmentasi, sehinggga tidak menyebar secara sembarangan. Efek dari keteraturan penyebaran perutean ini adalah penggunaan bandwith jaringan menjadi lebih efisien, lebih cepat mencapai konvergensi, dan lebih akurat dalam menentukan rute-rute terbaik menuju ke sebuah lokasi.

Untuk dapat menangani jaringan yang berskala besar, maka OSPF menerapkan konsep area dalam implementasinya, yaitu single area untuk jaringan berskala kecil dan multi area untuk jaringan berskala besar. Router yang menjalankan OSPF hanya akan bertukar informasi route (routing update) dengan router OSPF lainnya yang berada dalam satu autonomus system (AS). Router OSPF akan mengirimkan beberapa paket OSPF lainnya yang kesemuanya digunakan membentuk table routing. Pada OSPF dikenal kondisi adjency antar router. Sebelum router-router 
tersebut bertukar informasi routing, maka sebuah router harus terlebih dahulu mencapai kondisi adjency (bertetangga dan bersepakat) dengan router tetangganya. Router-router tidak akan bertukar routing update jika kondisi adjency belum tercapai [8].

OSPF mengumpulkan informasi link state dari router yang ada dan membangun sebuah grafik topologi dari jaringan. Adapun penelitian selanjutnya [11], menjelaskan untuk rute paket, OSPF menghitung shortest path tree untuk setiap rute menggunakan metode yang didasarkan pada algoritma dijkstra. Untuk menentukan jalur terpendek, OSPF membutuhkan pemberian bobot setiap link di jaringan. Link bobot didistribusikan sebagai link state.

Sebuah penelitian mengenai performa OSPF [12], menjelaskan bahwa algoritma dijkstra juga dikenal dengan algoritma link-state atau algoritma shortest path first (SPF). Algoritma ini memperbaiki informasi database dari informasi topologi. Algortima link-state memperbaiki pengetahuan dari jarak router dan bagaimana mereka interkoneksi. Penelitian lainnya [13], menjelaskan algortima djikstra digunakan untuk mencari jarak terpendek dari suatu graf berarah dengan bobot sisi yang tidak negatif. Algoritma ini akan mencari jalur dengan cost minimum di antara simpul yang ada dalam graf.

Berikut adalah proses algoritma djikstra pada teknik OSPF [14] :

1. Data yang masih berupa bit-bit kemudian dikemas menjadi paket-paket data.

2. Setiap router meng-update tabel routing.

3. Setelah meng-update tabel routing, router memberitahukan kepada router tetangganya berapa jarak dari router tersebut.

4. Tiap router mendapatkan informasi dari tabel routing yang telah di-update, kemudian algoritma dijkstra menghitung semua jarak yang menuju alamat tujuan.

5. Algoritma mencari best path ke alamat tujuan, jika alamat yang dituju sudah bertemu maka tiap router meng-update informasi pada tabel routing, jika tidak maka algoritma akan menghitung ulang untuk mencari best path.

6. Jika semua router telah diperiksa maka proses selesai, jika belum maka router akan memberi tahu kembali router tetangganya.

\subsection{Routing Information Protocol version 2 (RIPv2)}

Routing Information Protocol version 2 (RIPv2) merupakan protokol distance vector yang menggunakan hitungan lompatan dalam pengukurannya. Penelitian sebelumnya mengenai RIPv2 [15], menjelaskan RIPv2 mengevaluasi jalur terbaik antara host ke tujuan menggunakan metodologi hop count yang berjumlah maksimal 15 hop. Jalur yang memiliki hop count yang lebih rendah akan dipilih dan dimasukkan ke dalam tabel routing. RIPv2 menggunakan classless routing sehingga mendukung Variable Length Subnet Masks (VLSM). RIPv2 juga mendukung autentikasi MD5.

\section{METODE PENELITIAN}

Pada tulisan ini metode penelitian yang digunakan adalah :

1. Analisis. Pada tahapan ini dilakukan analisis literatur yang relevan. Literatur bersumber dari buku, jurnal ilmiah, dan penelitian yang membahas mengenai Open Shortest Path First (OSPF).

2. Desain. Tahapan ini berisikan bentuk prototipe topologi jaringan yang dikembangkan. Meliputi skenario jaringan secara fisik dan juga logika. Perancangan prototipe jaringan memanfaatkan software simulasi jaringan komputer Cisco Packet Tracer 6.1.1.

3. Pengembangan. Tahapan ini dilakukan untuk mengkonfigurasi prototipe topologi jaringan. Konfigurasi dilakukan pada setiap device yang ada di dalam prototipe jaringan, antara lain 
adalah PC, server, dan router. Konfigurasi routing protocol OSPF dilakukan di router dengan mengetikkan kode program pada jendela CLI router tersebut. Pengaturan router dilakukan untuk menghasilkan jalur terbaik untuk melewatkan paket data dalam jaringan.

4. Pengujian. Setelah prototipe jaringan selesai dikembangkan, setiap device dilakukan pengujian konektivitasnya.

\section{HASIL DAN PEMBAHASAN}

\subsection{Topologi Jaringan untuk Penelitian}

Topologi jaringan pada penelitian ini adalah seperti Gambar 1 berikut.

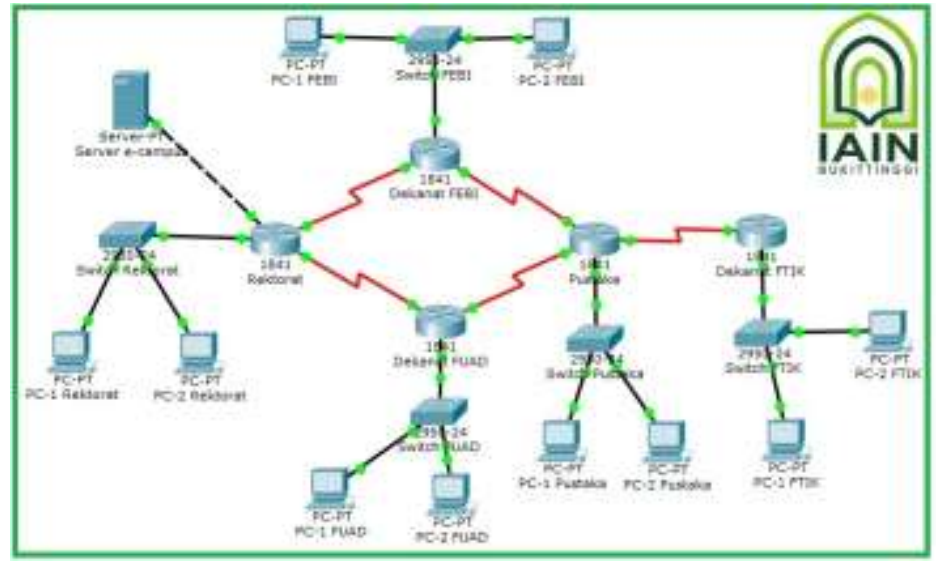

Gambar 1. Topologi Jaringan yang Digunakan Dalam Penelitian

Topologi jaringan di atas terdapat lima buah router yang memiliki alamat IP address pada port yang diaktifkan. Server e-campus yang terhubung ke router rektorat merupakan tujuan yang akan diakses oleh setiap komputer client. Routing OSPF dan RIPv2 akan menentukan jalur terbaik setiap client menuju server e-campus. Tabel 1 berikut ini adalah IP address pada masing-masing router.

Tabel 1. Konfigurasi Alamat Router

\begin{tabular}{|l|l|c|}
\hline \multicolumn{1}{|c|}{ Router } & \multicolumn{1}{|c|}{ Port : IP Address / Prefix } & Clock Rate \\
\hline \multirow{2}{*}{ Dekanat FTIK } & Fa0/0 : 192.172.12.1/24 & - \\
& Se0/0/0 $: 178.32 .4 .1 / 24$ & 72000 \\
\hline \multirow{5}{*}{ Pustaka } & Se0/0/0 :8.4.2.1/24 & - \\
& Se0/0/1 :212.10.0.1/24 & - \\
& $\mathrm{Fa} 0 / 0: 150.64 .26 .1 / 24$ & - \\
& $\mathrm{Se} 0 / 1 / 0: 178.32 .4 .2 / 24$ & - \\
\hline \multirow{3}{*}{ Dekanat FUAD } & $\mathrm{Se} 0 / 0 / 1: 8.4 .2 .2 / 24$ & 72000 \\
& $\mathrm{Fa} 0 / 0: 11.12 .13 .1 / 24$ & - \\
& $\mathrm{Se} 0 / 0 / 0: 172.17 .1 .2 / 24$ & - \\
\hline \multirow{5}{*}{ Dekanat FEBI } & $\mathrm{Se} 0 / 0 / 0: 212.10 .0 .2 / 24$ & 72000 \\
& $\mathrm{Fa} 0 / 0: 172.18 .1 .1 / 24$ & - \\
& $\mathrm{Se} 0 / 0 / 1: 43.15 .1 .1 / 24$ & - \\
\hline \multirow{5}{*}{ Rektorat } & $\mathrm{Se} 0 / 0 / 0: 43.15 .1 .2 / 24$ & 72000 \\
& $\mathrm{Fa} 0 / 0: 223.123 .3 .1 / 24$ & - \\
& $\mathrm{Se} 0 / 0 / 1: 172.17 .1 .1 / 24$ & 72000 \\
& $\mathrm{Fa} 0 / 1: 10.0 .0 .1 / 24$ & - \\
\hline
\end{tabular}


Konfigurasi IP address untuk setiap komputer yang terhubung ke router dapat dilihat pada Tabel 2 di bawah ini.

Tabel 2. Konfigurasi Alamat Komputer

\begin{tabular}{|l|l|l|}
\hline \multicolumn{1}{|c|}{ Perangkat } & \multicolumn{1}{c|}{ IP Address /Prefix } & \multicolumn{1}{c|}{ Default Gateway } \\
\hline Server e-campus & $223.123 .3 .2 / 24$ & 223.123 .3 .1 \\
\hline PC-1 Rektorat & $10.0 .0 .2 / 24$ & $10.0 .0 .1 / 24$ \\
\hline PC-2 Rektorat & $10.0 .0 .3 / 24$ & $10.0 .0 .1 / 24$ \\
\hline PC-1 FEBI & $172.18 .1 .2 / 24$ & 172.18 .1 .1 \\
\hline PC-2 FEBI & $172.18 .1 .3 / 24$ & 172.18 .1 .1 \\
\hline PC-1 FUAD & $11.12 .13 .2 / 24$ & 11.12 .13 .1 \\
\hline PC-2 FUAD & $11.12 .13 .3 / 24$ & 11.12 .13 .1 \\
\hline PC-1 Pustaka & $150.64 .26 .2 / 24$ & 150.64 .26 .1 \\
\hline PC-2 Pustaka & $150.64 .26 .3 / 24$ & 150.64 .26 .1 \\
\hline PC-1 FTIK & $192.172 .12 .2 / 24$ & 192.172 .12 .1 \\
\hline PC-2 FTIK & $192.172 .12 .3 / 24$ & 192.172 .12 .1 \\
\hline
\end{tabular}

\subsection{Konfigurasi Routing Protokol OSPF}

Pengaturan routing menggunakan protokol OSPF multiple area. Terdapat tiga buah area, yaitu area 0,10 , dan 20. Gambar 2 berikut ini merupakan pembagian area tersebut.

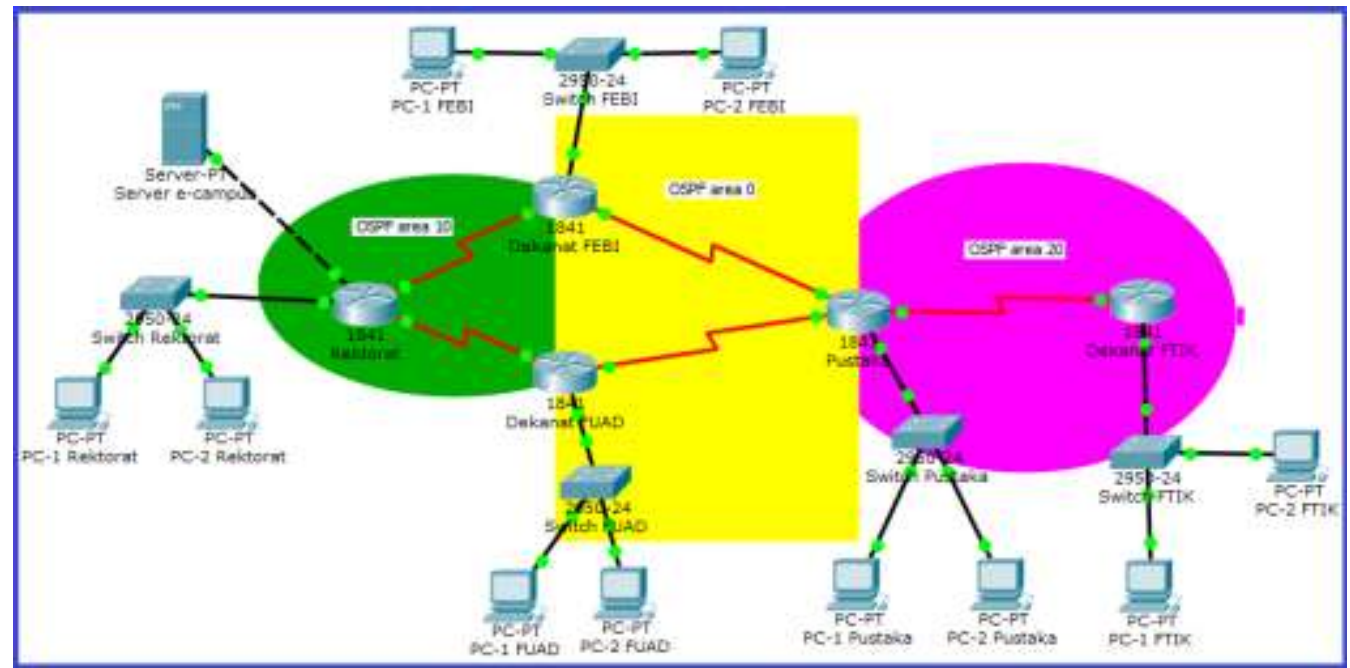

Gambar 2. Pembagian Multiple Area Routing Protocol OSPF

Pengaturan routing protocol OSPF pada setiap router adalah sebagai berikut : 
1. Router Rektorat.

Router>enable

Router\#configure terminal

Router(config)\#hostname Router-Rektorat

Router-Rektorat(config)\#router ospf 1

Router-Rektorat(config-router)\#network 223.123.3.0 0.0.0.255 area 10

Router-Rektorat(config-router)\#network 10.0.0.0 0.0.0.255 area 10

Router-Rektorat(config-router)\#network 43.15.1.0 0.0.0.255 area 10

Router-Rektorat(config-router)\#network 172.17.1.0 0.0.0.255 area 10

2. Router Dekanat FEBI.

Router>enable

Router\#configure terminal

Router(config)\#hostname Router-Dekanat_FEBI

Router-Dekanat_FEBI(config)\#router ospf 1

Router-Dekanat_FEBI(config-router)\#network 43.15.1.0 0.0.0.255 area 10

Router-Dekanat_FEBI(config-router)\#network 172.18.1.0 0.0.0.255 area 0

Router-Dekanat_FEBI(config-router)\#network 212.10.0.0 0.0.0.255 area 0

3. Router Dekanat FUAD.

Router>enable

Router\#configure terminal

Router(config)\#hostname Router-Dekanat_FUAD

Router-Dekanat_FUAD(config)\#router ospf 1

Router-Dekanat_FUAD(config-router)\#network 172.17.1.0 0.0.0.255 area 10

Router-Dekanat_FUAD(config-router)\#network 11.12.13.0 0.0.0.255 area 0

Router-Dekanat_FUAD(config-router)\#network 8.4.2.0 0.0.0.255 area 0

4. Router Pustaka.

Router >enable

Router\#configure terminal

Router(config)\#hostname Router-Pustaka

Router-Pustaka(config)\#router ospf 1

Router-Pustaka(config-router)\#network 212.10.0.0 0.0.0.255 area 0

Router-Pustaka(config-router)\#network 8.4.2.0 0.0.0.255 area 0

Router-Pustaka(config-router)\#network 178.32.4.0 0.0.0.255 area 20

Router-Pustaka(config-router)\#network 150.64.26.0 0.0.0.255 area 20

5. Router Dekanat FTIK.

Router >enable

Router\#configure terminal

Router(config)\#hostname Router-Dekanat_FTIK

Router-Dekanat_FTIK(config)\#router ospf 1

Router-Dekanat_FTIK(config-router)\#network 178.32.4.0 0.0.0.255 area 20

Router-Dekanat_FTIK(config-router)\#network 192.172.12.0 0.0.0.255 area 20

\subsection{Analisis Hasil Penerapan Routing Protokol OSPF}

Analisis setelah konfigurasi routing protocol OSPF diterapkan adalah sebagai berikut.

1. Konektivitas jaringan diuji dengan perintah ping, yang merupakan protokol ICMP (Internet Control Messaging Protocol). Ping (Packet Internet Groper) digunakan untuk memeriksa waktu konektivitas sebuah interface pada suatu jaringan. Pengujian konektivitas jaringan dengan mengirimkan paket ping dari semua device ke server e-campus. Tabel 3 berikut ini adalah hasilnya. 
Tabel 3. Hasil Pengiriman Ping

\begin{tabular}{|c|c|c|}
\hline \multirow{2}{*}{ Device } & \multicolumn{2}{|c|}{ Hasil Ping } \\
\hline & OSPF & RIPv2 \\
\hline Router Rektorat & $\mathrm{min} / \mathrm{max} / \mathrm{avg}=0 / 1 / 0 \mathrm{~ms}$ & $\mathrm{~min} / \mathrm{max} / \mathrm{avg}=0 / 4 / 2 \mathrm{~ms}$ \\
\hline Router Pustaka & $\min / \max / \operatorname{avg}=2 / 9 / 1 \mathrm{~ms}$ & $\mathrm{~min} / \mathrm{max} / \mathrm{avg}=2 / 16 / 5 \mathrm{~ms}$ \\
\hline Router Dekanat FTIK & $\mathrm{min} / \mathrm{max} / \mathrm{avg}=3 / 10 / 2 \mathrm{~ms}$ & $\mathrm{~min} / \mathrm{max} / \mathrm{avg}=3 / 54 / 23 \mathrm{~ms}$ \\
\hline Router Dekanat FUAD & $\mathrm{min} / \mathrm{max} / \mathrm{avg}=1 / 1 / 1 \mathrm{~ms}$ & $\mathrm{~min} / \mathrm{max} / \mathrm{avg}=1 / 32 / 7 \mathrm{~ms}$ \\
\hline Router Dekanat FEBI & $\mathrm{min} / \mathrm{max} / \mathrm{avg}=1 / 4 / 1 \mathrm{~ms}$ & $\mathrm{~min} / \mathrm{max} / \mathrm{avg}=2 / 16 / 8 \mathrm{~ms}$ \\
\hline PC-1 Rektorat & $\mathrm{min} / \mathrm{max} / \mathrm{avg}=0 / 1 / 0 \mathrm{~ms}$ & $\mathrm{~min} / \mathrm{max} / \mathrm{avg}=2 / 16 / 4 \mathrm{~ms}$ \\
\hline PC-2 Rektorat & $\mathrm{min} / \mathrm{max} / \mathrm{avg}=0 / 4 / 1 \mathrm{~ms}$ & $\mathrm{~min} / \mathrm{max} / \mathrm{avg}=1 / 4 / 2 \mathrm{~ms}$ \\
\hline PC-1 FEBI & $\mathrm{min} / \mathrm{max} / \mathrm{avg}=1 / 2 / 1 \mathrm{~ms}$ & $\mathrm{~min} / \mathrm{max} / \mathrm{avg}=1 / 11 / 3 \mathrm{~ms}$ \\
\hline PC-2 FEBI & $\mathrm{min} / \mathrm{max} / \mathrm{avg}=1 / 2 / 1 \mathrm{~ms}$ & $\mathrm{~min} / \mathrm{max} / \mathrm{avg}=1 / 29 / 8 \mathrm{~ms}$ \\
\hline PC-1 FUAD & $\mathrm{min} / \mathrm{max} / \mathrm{avg}=1 / 1 / 1 \mathrm{~ms}$ & $\mathrm{~min} / \mathrm{max} / \mathrm{avg}=1 / 12 / 3 \mathrm{~ms}$ \\
\hline PC-2 FUAD & $\min / \max / \mathrm{avg}=1 / 2 / 1 \mathrm{~ms}$ & $\min / \max / \mathrm{avg}=1 / 12 / 4 \mathrm{~ms}$ \\
\hline PC-1 Pustaka & $\mathrm{min} / \mathrm{max} / \mathrm{avg}=2 / 3 / 2 \mathrm{~ms}$ & $\mathrm{~min} / \mathrm{max} / \mathrm{avg}=2 / 13 / 7 \mathrm{~ms}$ \\
\hline PC-2 Pustaka & $\mathrm{min} / \mathrm{max} / \mathrm{avg}=1 / 2 / 1 \mathrm{~ms}$ & $\mathrm{~min} / \mathrm{max} / \mathrm{avg}=2 / 14 / 5 \mathrm{~ms}$ \\
\hline PC-1 FTIK & $\mathrm{min} / \mathrm{max} / \mathrm{avg}=3 / 3 / 3 \mathrm{~ms}$ & $\mathrm{~min} / \mathrm{max} / \mathrm{avg}=3 / 14 / 8 \mathrm{~ms}$ \\
\hline PC-2 FTIK & $\mathrm{min} / \mathrm{max} / \mathrm{avg}=1 / 4 / 1 \mathrm{~ms}$ & $\mathrm{~min} / \mathrm{max} / \mathrm{avg}=3 / 17 / 11 \mathrm{~ms}$ \\
\hline
\end{tabular}

Tabel 3 di atas menunjukkan waktu rata-rata pengiriman pesan ping pada OSPF berkisar dari 1-3 ms. Hasil ini menunjukkan konektivitas OSPF berlangsung stabil dan cepat. Sedangkan pada RIPv2 rata-rata waktunya adalah 2-23 ms, hasil ini lebih lambat dibandingkan dengan OSPF.

2. Jalur paket data. Perintah tracert digunakan untuk mencari jalur yang akan dilalui oleh paket data, tracert ini menggunakan protokol ICMP. Cara kerjanya adalah dengan mengirimkan ICMP messages yang disebut IP datagrams dengan parameter waktu yang disebut timeout. Tabel 4. Tabel 5 dan Tabel 6 berikut ini adalah hasil dari penelusuran jalur paket data pada topologi jaringan penelitian ini. Tujuan yang harus dicapai oleh setiap device adalah server ecampus. 
Tabel 4. Hasil Penelusuran Jalur Paket Data Pada Router

\begin{tabular}{|c|c|c|}
\hline \multirow{2}{*}{ Device } & \multicolumn{2}{|c|}{ Hasil Tracert } \\
\hline & OSPF & RIPv2 \\
\hline $\begin{array}{l}\text { Router } \\
\text { Rektorat }\end{array}$ & $1223.123 .3 .2: 1 \mathrm{msec} 0 \mathrm{msec} 0 \mathrm{msec}$ & $1223.123 .3 .2: 1 \mathrm{msec} 0 \mathrm{msec} 0 \mathrm{msec}$ \\
\hline $\begin{array}{l}\text { Router } \\
\text { Pustaka }\end{array}$ & 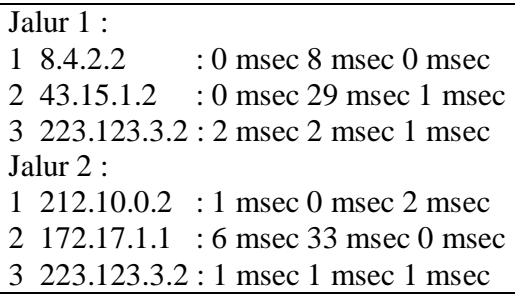 & 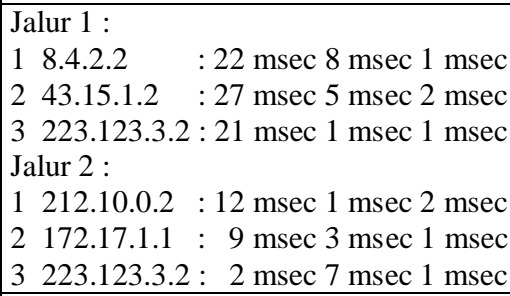 \\
\hline $\begin{array}{l}\text { Router } \\
\text { Dekanat } \\
\text { FTIK }\end{array}$ & 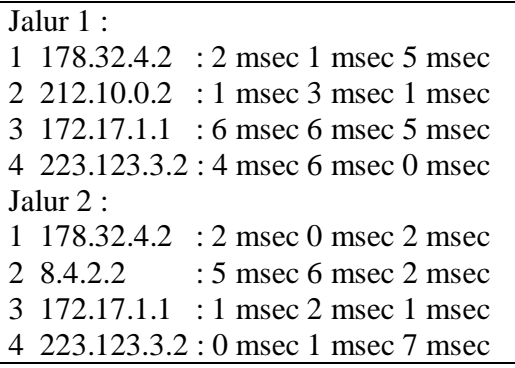 & 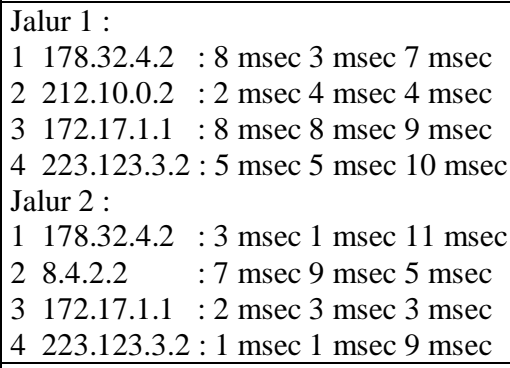 \\
\hline $\begin{array}{l}\text { Router } \\
\text { Dekanat } \\
\text { FUAD }\end{array}$ & $\begin{array}{ll}1 & 172.17 .1 .1: 0 \mathrm{msec} 0 \mathrm{msec} 5 \mathrm{msec} \\
2 & 223.123 .3 .2: 0 \mathrm{msec} 0 \mathrm{msec} 0 \mathrm{msec}\end{array}$ & $\begin{array}{ll}1 & 172.17 .1 .1: 5 \mathrm{msec} 0 \mathrm{msec} 1 \mathrm{msec} \\
2 & 223.123 .3 .2: 2 \mathrm{msec} 4 \mathrm{msec} 24 \mathrm{msec}\end{array}$ \\
\hline $\begin{array}{l}\text { Router } \\
\text { Dekanat } \\
\text { FEBI }\end{array}$ & $\begin{array}{ll}1 & 43.15 .1 .2: 0 \mathrm{msec} 0 \mathrm{msec} 1 \mathrm{msec} \\
2 & 223.123 .3 .2: 0 \mathrm{msec} 6 \mathrm{msec} 5 \mathrm{msec}\end{array}$ & $\begin{array}{ll}1 & 43.15 .1 .2: 4 \mathrm{msec} 6 \mathrm{msec} 3 \mathrm{msec} \\
2 & 223.123 .3 .2: 1 \mathrm{msec} 7 \mathrm{msec} 13 \mathrm{msec}\end{array}$ \\
\hline
\end{tabular}

Tabel 5. Hasil Penelusuran Jalur Paket Data Pada Komputer Client yang Memiliki Satu Jalur

\begin{tabular}{|l|lllrl|lllll|}
\hline \multirow{2}{*}{ Device } & \multicolumn{7}{|c|}{ Hasil Tracert } \\
\cline { 2 - 11 } & \multicolumn{7}{|c|}{ OSPF } & \multicolumn{5}{c|}{ RIPv2 } \\
\hline PC-1 & 1 & $1 \mathrm{~ms}$ & $0 \mathrm{~ms}$ & $0 \mathrm{~ms}$ & 10.0 .0 .1 & $11 \mathrm{~ms}$ & $0 \mathrm{~ms}$ & $1 \mathrm{~ms}$ & 10.0 .0 .1 \\
Rektorat & 2 & $0 \mathrm{~ms}$ & $1 \mathrm{~ms}$ & $1 \mathrm{~ms}$ & 223.123 .3 .2 & 2 & $0 \mathrm{~ms}$ & $1 \mathrm{~ms}$ & $1 \mathrm{~ms}$ & 223.123 .3 .2 \\
\hline PC-2 & 1 & $1 \mathrm{~ms}$ & $0 \mathrm{~ms}$ & $0 \mathrm{~ms}$ & 10.0 .0 .1 & 1 & $4 \mathrm{~ms}$ & $1 \mathrm{~ms}$ & $0 \mathrm{~ms}$ & 10.0 .0 .1 \\
Rektorat & 2 & $1 \mathrm{~ms}$ & $0 \mathrm{~ms}$ & $0 \mathrm{~ms}$ & 223.123 .3 .2 & 2 & $2 \mathrm{~ms}$ & $0 \mathrm{~ms}$ & $0 \mathrm{~ms}$ & 223.123 .3 .2 \\
\hline \multirow{2}{*}{ PC-1 } & 1 & $1 \mathrm{~ms}$ & $0 \mathrm{~ms}$ & $0 \mathrm{~ms}$ & 172.18 .1 .1 & 1 & $1 \mathrm{~ms}$ & $1 \mathrm{~ms}$ & $0 \mathrm{~ms}$ & 172.18 .1 .1 \\
FEBI & 2 & $0 \mathrm{~ms}$ & $1 \mathrm{~ms}$ & $1 \mathrm{~ms}$ & 43.15 .1 .2 & 2 & $1 \mathrm{~ms}$ & $0 \mathrm{~ms}$ & $1 \mathrm{~ms}$ & 43.15 .1 .2 \\
& 3 & $1 \mathrm{~ms}$ & $0 \mathrm{~ms}$ & $0 \mathrm{~ms}$ & 223.123 .3 .2 & 3 & $2 \mathrm{~ms}$ & $0 \mathrm{~ms}$ & $1 \mathrm{~ms}$ & 223.123 .3 .2 \\
\hline \multirow{2}{*}{ PC-2 } & 1 & $1 \mathrm{~ms}$ & $0 \mathrm{~ms}$ & $0 \mathrm{~ms}$ & 172.18 .1 .1 & 1 & $2 \mathrm{~ms}$ & $0 \mathrm{~ms}$ & $0 \mathrm{~ms}$ & 172.18 .1 .1 \\
FEBI & 2 & $0 \mathrm{~ms}$ & $1 \mathrm{~ms}$ & $1 \mathrm{~ms}$ & 43.15 .1 .2 & 2 & $1 \mathrm{~ms}$ & $4 \mathrm{~ms}$ & $1 \mathrm{~ms}$ & 43.15 .1 .2 \\
& 3 & $0 \mathrm{~ms}$ & $1 \mathrm{~ms}$ & $1 \mathrm{~ms}$ & 223.123 .3 .2 & 3 & $0 \mathrm{~ms}$ & $1 \mathrm{~ms}$ & $3 \mathrm{~ms}$ & 223.123 .3 .2 \\
\hline \multirow{2}{*}{ PC-1 } & 1 & $1 \mathrm{~ms}$ & $0 \mathrm{~ms}$ & $0 \mathrm{~ms}$ & 11.12 .13 .1 & 1 & $2 \mathrm{~ms}$ & $1 \mathrm{~ms}$ & $1 \mathrm{~ms}$ & 11.12 .13 .1 \\
FUAD & 2 & $0 \mathrm{~ms}$ & $0 \mathrm{~ms}$ & $1 \mathrm{~ms}$ & 172.17 .1 .1 & 2 & $1 \mathrm{~ms}$ & $0 \mathrm{~ms}$ & $1 \mathrm{~ms}$ & 172.17 .1 .1 \\
& 3 & $1 \mathrm{~ms}$ & $0 \mathrm{~ms}$ & $0 \mathrm{~ms}$ & 223.123 .3 .2 & 3 & $1 \mathrm{~ms}$ & $1 \mathrm{~ms}$ & $0 \mathrm{~ms}$ & 223.123 .3 .2 \\
\hline \multirow{2}{*}{ PC-2 } & 1 & $1 \mathrm{~ms}$ & $1 \mathrm{~ms}$ & $0 \mathrm{~ms}$ & 11.12 .13 .1 & 1 & $2 \mathrm{~ms}$ & $1 \mathrm{~ms}$ & $1 \mathrm{~ms}$ & 11.12 .13 .1 \\
FUAD & 2 & $1 \mathrm{~ms}$ & $0 \mathrm{~ms}$ & $0 \mathrm{~ms}$ & 172.17 .1 .1 & 2 & $2 \mathrm{~ms}$ & $0 \mathrm{~ms}$ & $1 \mathrm{~ms}$ & 172.17 .1 .1 \\
& 3 & $1 \mathrm{~ms}$ & $0 \mathrm{~ms}$ & $0 \mathrm{~ms}$ & 223.123 .3 .2 & 3 & $1 \mathrm{~ms}$ & $1 \mathrm{~ms}$ & $0 \mathrm{~ms}$ & 223.123 .3 .2 \\
\hline
\end{tabular}


Tabel 6. Hasil Penelusuran Jalur Paket Data Pada Komputer Client yang Memiliki Dua Jalur

\begin{tabular}{|c|c|c|c|c|c|c|c|c|}
\hline \multirow{2}{*}{ Device } & \multicolumn{8}{|c|}{ Hasil Tracert } \\
\hline & \multicolumn{4}{|c|}{ OSPF } & \multicolumn{4}{|c|}{ RIPv2 } \\
\hline \multirow{10}{*}{$\begin{array}{l}\text { PC-1 } \\
\text { Pustaka }\end{array}$} & Jalur 1: & & & & Jalur 1: & & & \\
\hline & $11 \mathrm{~ms}$ & $0 \mathrm{~ms}$ & $0 \mathrm{~ms}$ & 150.64 .26 .1 & $12 \mathrm{~ms}$ & $1 \mathrm{~ms}$ & $1 \mathrm{~ms}$ & 150.64 .26 .1 \\
\hline & $21 \mathrm{~ms}$ & $0 \mathrm{~ms}$ & $0 \mathrm{~ms}$ & 212.10 .0 .2 & $21 \mathrm{~ms}$ & $4 \mathrm{~ms}$ & $4 \mathrm{~ms}$ & 212.10.0.2 \\
\hline & $31 \mathrm{~ms}$ & $1 \mathrm{~ms}$ & $2 \mathrm{~ms}$ & 43.15 .1 .2 & $34 \mathrm{~ms}$ & $2 \mathrm{~ms}$ & $9 \mathrm{~ms}$ & 43.15 .1 .2 \\
\hline & $41 \mathrm{~ms}$ & $3 \mathrm{~ms}$ & $0 \mathrm{~ms}$ & 223.123 .3 .2 & $43 \mathrm{~ms}$ & $3 \mathrm{~ms}$ & $5 \mathrm{~ms}$ & 223.123 .3 .2 \\
\hline & Jalur 2 : & & & & Jalur 2 : & & & \\
\hline & $11 \mathrm{~ms}$ & $0 \mathrm{~ms}$ & $0 \mathrm{~ms}$ & 150.64 .26 .1 & $14 \mathrm{~ms}$ & $0 \mathrm{~ms}$ & $3 \mathrm{~ms}$ & 150.64 .26 .1 \\
\hline & $21 \mathrm{~ms}$ & $0 \mathrm{~ms}$ & $0 \mathrm{~ms}$ & 8.4.2.2 & $21 \mathrm{~ms}$ & $1 \mathrm{~ms}$ & $4 \mathrm{~ms}$ & 8.4.2.2 \\
\hline & $31 \mathrm{~ms}$ & $2 \mathrm{~ms}$ & $1 \mathrm{~ms}$ & 43.15 .1 .2 & $36 \mathrm{~ms}$ & $2 \mathrm{~ms}$ & $7 \mathrm{~ms}$ & 43.15 .1 .2 \\
\hline & $44 \mathrm{~ms}$ & $0 \mathrm{~ms}$ & $1 \mathrm{~ms}$ & 223.123.3.2 & $48 \mathrm{~ms}$ & $0 \mathrm{~ms}$ & $5 \mathrm{~ms}$ & 223.123 .3 .2 \\
\hline \multirow{9}{*}{$\begin{array}{l}\text { PC-2 } \\
\text { Pustaka }\end{array}$} & $\begin{array}{l}\text { Jalur 1: } \\
11 \mathrm{~ms}\end{array}$ & $0 \mathrm{~ms}$ & $1 \mathrm{~ms}$ & 150.64 .26 .1 & $\begin{array}{l}\text { Jalur } 1 \text { : } \\
13 \mathrm{~ms}\end{array}$ & $1 \mathrm{~ms}$ & $2 \mathrm{~ms}$ & 150.64 .26 .1 \\
\hline & $20 \mathrm{~ms}$ & $0 \mathrm{~ms}$ & $0 \mathrm{~ms}$ & 212.10 .0 .2 & $22 \mathrm{~ms}$ & $2 \mathrm{~ms}$ & $1 \mathrm{~ms}$ & 212.10 .0 .2 \\
\hline & $31 \mathrm{~ms}$ & $1 \mathrm{~ms}$ & $0 \mathrm{~ms}$ & 43.15 .1 .2 & $32 \mathrm{~ms}$ & $1 \mathrm{~ms}$ & $3 \mathrm{~ms}$ & 43.15 .1 .2 \\
\hline & $41 \mathrm{~ms}$ & $2 \mathrm{~ms}$ & $2 \mathrm{~ms}$ & 223.123 .3 .2 & $41 \mathrm{~ms}$ & $2 \mathrm{~ms}$ & $1 \mathrm{~ms}$ & 223.123 .3 .2 \\
\hline & Jalur 2 : & & & & Jalur 2 : & & & \\
\hline & $11 \mathrm{~ms}$ & $0 \mathrm{~ms}$ & $0 \mathrm{~ms}$ & 150.64 .26 .1 & $14 \mathrm{~ms}$ & $2 \mathrm{~ms}$ & $4 \mathrm{~ms}$ & 150.64 .26 .1 \\
\hline & $21 \mathrm{~ms}$ & $0 \mathrm{~ms}$ & $0 \mathrm{~ms}$ & 8.4.2.2 & $21 \mathrm{~ms}$ & $1 \mathrm{~ms}$ & $2 \mathrm{~ms}$ & 8.4.2.2 \\
\hline & $31 \mathrm{~ms}$ & $1 \mathrm{~ms}$ & $2 \mathrm{~ms}$ & 43.15 .1 .2 & $32 \mathrm{~ms}$ & $1 \mathrm{~ms}$ & $1 \mathrm{~ms}$ & 43.15 .1 .2 \\
\hline & $40 \mathrm{~ms}$ & $1 \mathrm{~ms}$ & $1 \mathrm{~ms}$ & 223.123 .3 .2 & $41 \mathrm{~ms}$ & $1 \mathrm{~ms}$ & $3 \mathrm{~ms}$ & 223.123 .3 .2 \\
\hline \multirow{11}{*}{$\begin{array}{l}\text { PC-1 } \\
\text { FTIK }\end{array}$} & $\begin{array}{l}\text { Jalur 1: } \\
11 \mathrm{~ms}\end{array}$ & $0 \mathrm{~ms}$ & $0 \mathrm{~ms}$ & 192.172 .12 .1 & $\begin{array}{l}\text { Jalur } 1 \text { : } \\
1 \quad 1 \mathrm{~ms}\end{array}$ & $2 \mathrm{~ms}$ & $1 \mathrm{~ms}$ & 192.172 .12 .1 \\
\hline & $20 \mathrm{~ms}$ & $1 \mathrm{~ms}$ & $0 \mathrm{~ms}$ & 178.32.4.2 & $20 \mathrm{~ms}$ & $1 \mathrm{~ms}$ & $2 \mathrm{~ms}$ & 178.32.4.2 \\
\hline & $31 \mathrm{~ms}$ & $2 \mathrm{~ms}$ & $1 \mathrm{~ms}$ & 8.4.2.2 & $32 \mathrm{~ms}$ & $6 \mathrm{~ms}$ & $1 \mathrm{~ms}$ & 8.4.2.2 \\
\hline & $42 \mathrm{~ms}$ & $2 \mathrm{~ms}$ & $2 \mathrm{~ms}$ & 43.15 .1 .2 & $43 \mathrm{~ms}$ & $4 \mathrm{~ms}$ & $3 \mathrm{~ms}$ & 43.15 .1 .2 \\
\hline & $52 \mathrm{~ms}$ & $0 \mathrm{~ms}$ & $2 \mathrm{~ms}$ & 223.123 .3 .2 & $58 \mathrm{~ms}$ & $3 \mathrm{~ms}$ & $1 \mathrm{~ms}$ & 223.123 .3 .2 \\
\hline & Jalur 2: & & & & Jalur 2: & & & \\
\hline & $11 \mathrm{~ms}$ & $0 \mathrm{~ms}$ & $0 \mathrm{~ms}$ & 192.172 .12 .1 & $12 \mathrm{~ms}$ & $0 \mathrm{~ms}$ & $5 \mathrm{~ms}$ & 192.172 .12 .1 \\
\hline & $21 \mathrm{~ms}$ & $3 \mathrm{~ms}$ & $0 \mathrm{~ms}$ & 178.32 .4 .2 & $22 \mathrm{~ms}$ & $3 \mathrm{~ms}$ & $2 \mathrm{~ms}$ & 178.32.4.2 \\
\hline & $31 \mathrm{~ms}$ & $1 \mathrm{~ms}$ & $1 \mathrm{~ms}$ & 212.10.0.2 & $36 \mathrm{~ms}$ & $1 \mathrm{~ms}$ & $2 \mathrm{~ms}$ & 212.10.0.2 \\
\hline & $43 \mathrm{~ms}$ & $1 \mathrm{~ms}$ & $0 \mathrm{~ms}$ & 43.15 .1 .2 & $45 \mathrm{~ms}$ & $1 \mathrm{~ms}$ & $1 \mathrm{~ms}$ & 43.15 .1 .2 \\
\hline & $51 \mathrm{~ms}$ & $0 \mathrm{~ms}$ & $1 \mathrm{~ms}$ & 223.123 .3 .2 & $52 \mathrm{~ms}$ & $1 \mathrm{~ms}$ & $1 \mathrm{~ms}$ & 223.123 .3 .2 \\
\hline \multirow{11}{*}{$\begin{array}{l}\text { PC-2 } \\
\text { FTIK }\end{array}$} & $\begin{array}{l}\text { Jalur 1: } \\
11 \mathrm{~ms}\end{array}$ & $0 \mathrm{~ms}$ & $0 \mathrm{~ms}$ & 192.172 .12 .1 & $\begin{array}{l}\text { Jalur } 1 \text { : } \\
12 \mathrm{~ms}\end{array}$ & $1 \mathrm{~ms}$ & $4 \mathrm{~ms}$ & 192.172 .12 .1 \\
\hline & $21 \mathrm{~ms}$ & $0 \mathrm{~ms}$ & $1 \mathrm{~ms}$ & 178.32 .4 .2 & $23 \mathrm{~ms}$ & $1 \mathrm{~ms}$ & $2 \mathrm{~ms}$ & 178.32 .4 .2 \\
\hline & $30 \mathrm{~ms}$ & $1 \mathrm{~ms}$ & $1 \mathrm{~ms}$ & 212.10 .0 .2 & $31 \mathrm{~ms}$ & $2 \mathrm{~ms}$ & $2 \mathrm{~ms}$ & 212.10 .0 .2 \\
\hline & $46 \mathrm{~ms}$ & $2 \mathrm{~ms}$ & $1 \mathrm{~ms}$ & 43.15 .1 .2 & $47 \mathrm{~ms}$ & $3 \mathrm{~ms}$ & $1 \mathrm{~ms}$ & 43.15 .1 .2 \\
\hline & $53 \mathrm{~ms}$ & $1 \mathrm{~ms}$ & $1 \mathrm{~ms}$ & 223.123 .3 .2 & $53 \mathrm{~ms}$ & $1 \mathrm{~ms}$ & $1 \mathrm{~ms}$ & 223.123 .3 .2 \\
\hline & Jalur 2 : & & & & Jalur 2 : & & & \\
\hline & $10 \mathrm{~ms}$ & $0 \mathrm{~ms}$ & $1 \mathrm{~ms}$ & 192.172 .12 .1 & $12 \mathrm{~ms}$ & $2 \mathrm{~ms}$ & $2 \mathrm{~ms}$ & 192.172 .12 .1 \\
\hline & $21 \mathrm{~ms}$ & $1 \mathrm{~ms}$ & $1 \mathrm{~ms}$ & 178.32.4.2 & $23 \mathrm{~ms}$ & $2 \mathrm{~ms}$ & $4 \mathrm{~ms}$ & 178.32.4.2 \\
\hline & $32 \mathrm{~ms}$ & $2 \mathrm{~ms}$ & $1 \mathrm{~ms}$ & 8.4.2.2 & $32 \mathrm{~ms}$ & $4 \mathrm{~ms}$ & $2 \mathrm{~ms}$ & 8.4.2.2 \\
\hline & $42 \mathrm{~ms}$ & $3 \mathrm{~ms}$ & $2 \mathrm{~ms}$ & 43.15 .1 .2 & $47 \mathrm{~ms}$ & $8 \mathrm{~ms}$ & $5 \mathrm{~ms}$ & 43.15 .1 .2 \\
\hline & $52 \mathrm{~ms}$ & $7 \mathrm{~ms}$ & $2 \mathrm{~ms}$ & 223.123 .3 .2 & $51 \mathrm{~ms}$ & $9 \mathrm{~ms}$ & $3 \mathrm{~ms}$ & 223.123 .3 .2 \\
\hline
\end{tabular}

Berdasarkan Tabel 4, Tabel 5, dan Tabel 6 di atas, OSPF memberikan alternatif jalur terbaik dalam jaringan, dimana terdapat perbedaan waktu yang signifikan diantara pilihan jalur yang ada. Menggunakan RIPv2 tidak didapatkan hasil alternatif untuk jalur terbaik. Setiap jalur memiliki waktu yang hampir sama besarnya.

\section{KESIMPULAN}

Berdasarkan pada percobaan yang telah dilakukan, protokol routing OSPF lebih baik dibandingkan dengan RIPv2. OSPF memberikan pilihan jalur terbaik (best path) dalam melewatkan paket data. Pemilihan jalur terbaik berdasarkan pada waktu yang dibutuhkan untuk mengakses setiap alternatif pilihan router yang akan dilewati. 
Algoritma dijkstra yang digunakan pada OSPF menghitung rute dengan nilai beban terkecil (minimum metric cost) dan bandwith terbesar yang disimpan ke dalam basis data perutean atau peta jaringan (link state). OSPF menentukan jalur terbaik dalam jaringan berdasarkan peta ini.

\section{DAFTAR PUSTAKA}

[1] Wahana Komputer. 2010. Cara Mudah Membangun Jaringan Komputer \& Internet. Jakarta : Mediakita.

[2] Nugroho, Heru. 2015. Matematika Diskrit dan Implementasinya dalam Dunia Teknologi Informasi. Yogyakarta : Deepublish.

[3] Rahmiati, Pauline, Dwi Aryanta, dan Taufiq Agung Priyadi. 2014. Perancangan dan analisis Perbandingan Implementasi OSPF pada Jaringan IPv4 dan IPv6. Jurnal ELKOMIKA, Vol. 2, No. 1, hal. 40-52, Januari-Juni.

[4] Lin, Y.D., Fred Baker, and R.H. Hwang. 2012. Computer Network An Open Source Approuch. McGraw - Hill International Edition.

[5] Sofana, Iwan. 2008. Membangun Jaringan Komputer, Membuat Jaringan Komputer (Wire \& Wireless) untuk Pengguna Windows dan Linux. Bandung : Informatika.

[6] Achmad. 2015. Implementasi Routing Protocol Open Shortest Path First (OSPF) pada Model Topology Ring. Faktor Exacta Jurnal Ilmiah Teknologi, Vol. 8, No. 2, hal. 92-99.

[7] Wijaya, Hendra. 2006. Belajar Sendiri Cisco ADSL Router, PIX Firewall, dan VPN. Jakarta : PT. Elex Media Komputindo.

[8] Kusuma, Aprianto Pudji Adi, dan Asmunin. 2016. Implementasi Simple Port Knocking pada Dynamic Routing (OSPF) Menggunakan Simulasi GNS3. Jurnal Manajemen Informatika, Vol. 5, No. 2, hal. 7-17.

[9] Asigbe, Dagadzor F., et al. 2016. Performance Analysis Of Interior Gateway Routing Protocol (Eigrp) Over Open Shortest Path First (Ospf) Protocol. International Journal Of Scientific \& Technology Research (IJSTR), Vol. 5, No. 9, pp. 111-117, September.

[10] Nurhayati, Ade, dan Mikha Efrata Sihaloho. Simulasi Perbandingan Protokol Routing OSPF dan ISIS Menggunakan GNS 3. Jurnal ICT Penelitian dan Penerapan Teknologi Akademi Teknik Telekomunikasi Sandhy Putra Jakarta, hal. 35-39.

[11] Negara, Ridha Muldina, dan Rohmat Tulloh. 2017. Analisis Simulasi Penerapan Algoritma OSPF Menggunakan RouteFlow pada Jaringan Software Defined Network (SDN). Jurnal Infotel, Vol. 9, No. 1, hal. 75-83, Februari.

[12] Santoso, Kukuh Aris. 2016. Konfigurasi dan Analisis Performansi Routing OSPF pada Jaringan LAN dengan Simulator Cisco Packet Tracer Versi 6.2. Jurnal Kajian Teknik Elektro, Vol. 1, No. 1, hal. 67-78.

[13] Rigi C.R, et al. 2014. Shortest Path Routing Algorithm in Wireless Sensor Network - A Review. International Journal Of Scientific Research And Education (IJSAE), Vol. 2, No. 3, pp. 407-413, Maret.

[14] Villasica, Yovie Dewi, dan Naemah Mubarakah. 2014. Analisis Kinerja Routing Dinamis dengan Teknik OSPF (Open Shortest Path First) pada Topologi Mesh dalam Jaringan Local Area Network (LAN) Menggunakan Cisco Packet Tracer. Jurnal Singuda Ensikom, Vol. 7, No. 3, hal. 125-130, Juni.

[15] Musril, Hari Antoni. 2015. Analisis Unjuk Kerja RIPv2 dan EIGRP dalam Dynamic Routing Protocol. JETT, Vol. 2, No. 2, hal. 116-124, Desember. 